\title{
Peningkatan Nilai Ekonomis Batik Tulis dari Daun Sirih (Batik D'Suru)
}

\author{
Andri Harmoro Kusumo Broto, Rusbiyanti Sripeni, Sofyan Mahardika Rahardi, Mega Andriana Jane, \\ Kinanti Ayu Wigaringtyas ${ }^{1)}$ Abdullah G Toda, Ndaru Handian Dhuhava ${ }^{2)}$

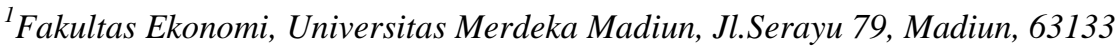 \\ E-mail: andri@unmer-madiun.ac.id \\ ${ }^{2}$ Program Studi Pertanian, Universitas Merdeka Madiun, Jl.Serayu 79, Madiun, 63133 \\ E-mail: andri@unmer-madiun.ac.id
}

\begin{abstract}
Batik is a picture art that is poured in a piece of cloth that is one of the Indonesian nation's identity that is recognized as World heritage. Unesco has set Batik as a Masterpieces of the Oral and the Intangible Heritage of Humanity on October 2, 2009. In Indonesia, Batik has expanded and penetrated the market share as the development of fashion in the world. Motives that exist in the market is also various types and apparently. Among others: Batik Mega Mendung, Batik Parang Rusak, Batik Kawung, etc. Which makes each type of batik has a different aesthetic value is different its uniqueness.. Dyeing techniques also vary from dyeing techniques, connective techniques, jumputan techniques etc.. Seeing this opportunity encourages the emergence of the idea of making Batik, but replace the use of the night with Leaf Betel. Leaf Betel itself is only used as medicine or herbal medicine by the surrounding community. With this idea, in addition to raising the economic value of Leaf Betel, the original legacy of Indonesia can also be preserved. Starting from drawing sketches on mori cloth, then burst the Batik motif with Scratches Ginger Leaf Betel on it using Nails. After this step is passed, continued the coloring, for staining time required about 1-2 hours for 1x1 meter sized fabric. The results are sold in the form of batik cloth, and marketed through social media, and sold directly in the area of Madiun and surrounding areas.
\end{abstract}

Keywords—: Batik; Leaf Betel; Heritage of Indonesia.

\section{PENDAHULUAN}

Wirausaha merupakan salah satu peluang usaha untuk mengatasi masalah meningkatkan jumlah pengangguran. Selain menguntungkan dari segi ekonomi sebagai besar kegiatan wirausaha juga sangat membantu usaha-usaha dalam memenuhi kebutuhan masyarakat banyak, menciptakan lapangan pekerjaan, baik secara langsung maupun tidak langsung.

Dewasa ini menjadi seorang wirausaha sangat diminati dikalangan masyarakat Indonesia terutama generasi mudanya. Mulai dari menjadi pengusaha makanan, pakaian, alat elektronik, bahkan seni mereka geluti. Melihat peluang itu kami berpikiran juga untuk membuka lowongan pekerjaan terutama untuk orang disekitar tempat tinggal kami. Salah satunya mendirikan usaha Batik.

Mengapa kita memilih Batik? Batik sendiri merupakan seni gambar yang dituangkan dalam selembar kain yang merupakan salah satu identitas bangsa Indonesia yang diakui Dunia. Batik yang kita temui dalam kehidupan sehari - hari sangat beragam jenis corak dan motifnya. Mulai dari Batik Parang Rusak, Batik Mega Mendung, hingga Batik Pring Sedapur khas daerah kami, Magetan. Batik yang biasa kita temui dipasaran biasanya menggunakan bahan lilin untuk membuat motifnya. Dengan tehnik pewarnaan di celup atau di tulis menggunakan canting. Bahkan sekarang ini, pengusaha Batik mulai beralih ke teknologi hingga muncul yang biasa kita sebut Batik Print.

Dengan kreatifitas dan inovasi kami berpikiran untuk mengganti bahan baku pembuat motif Batik dari bahan lilin kami gantikan dengan bahan alami. Daun Sirih yang kami pikirkan untuk bisa menggantikan fungsi lilinnya. Dengan alasan goresan getah dari Daun Sirih ini jika terkena baju atau kain tidak mudah hilang, atau tidak mudah luntur. Kami melakukan beberapa kali percobaan dan ternyata Daun Sirih memang bisa digunakan sebagai pengganti lilin pada Batik.

Tanaman sirih (Piper betle L) merupakan tanaman yang bersifat antifungi, antimikroba dan antioksidan. Hal ini disebabkan karena didalam ekstrak daun sirih mengandung minyak atsiri, tanin, fenoil, flavonoid, riboflavin, asam nikotat, sehingga dapat digunakan sebagai pengawet alami (Dalimatra, 2008). Komponen-komponen ini mampu mencegah adanya bakteri patogen dalam makanan yang diketahui sebagai pembusuk pada makanan.

Menurut Sholikhah (2006) senyawa fitokimia yang terkandung dalam daun sirih merah yakni alkoloid, saponin, tannin dan flavonoid. Sedangkan menurut Sudewo (2005) dari hasil kromotogam dapat dilihat bahwa daun sirih merah mengandung flavonoid, polifenolad, tannin dan minyak atsiri.

Flavonoid adalah kelompok senyawa fenol yang terbesar ditemukan dialam. Senyawa ini merupakan zat warna merah, ungu, biru dan sebagian kuning yang ditemukan dalam tumbuh-tumbuhan (Harbrone, 1987). Flavonoid dapat dikasifikasikan menjadi 3 yaitu flavoniod, isoflavonoid dan neoflavonoid. Flavonoid inilah yang menjadikan warna merah pada bekas goresan daun sirih. 
Website : http://dayamas.unmermadiun.ac.id/index.php/dayamas

Daun Sirih juga merupakan salah satu bahan alami yang mudah kita jumpai di sekitar tempat tinggal dan biasanya hanya digunakan sebagai bahan campuran jamu yang bernilai jual sangat rendah. Melihat keadaan tersebut mendukung bahwa nilai guna Daun Sirih sebenarnya bisa dijadikan nilai jual yang sangat menjanjikan jika diolah dengan tepat dan menarik.

\section{METODE PELAKSANAAN}

\section{A. Branding Produk}

Produk kami bermerk D'Suru ialah Batik Tulis yang motifnya digambar menggunakan getah daun Sirih. Sebenarnya Motif Batik sendiri terbuat dari bahan lilin Malam yang dipanaskan. Selain itu pada masyarakat sekitar, Daun sirih Hanya digunakan sebagai bahan jamu/ obat yang memiliki nilai jualyang sangat murah. Untuk meningkatkan nilai jualnya kami disini mencoba membuat perbedaan produk yang dapat meningkatkan nilai jual daun sirih dengan tetap mengangkat citra kain Batik asli budaya Indonesia. Berikut Profil dari Usaha kami :

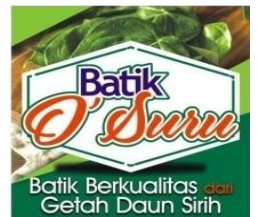

Perusahaan : D'Suru

Bidang Usaha : Industri Kreatif (Kain Batik)

Jenis Usaha : Milik Sendiri

Alamat

: Jalan Kalimantan RT 2 RW 2 Desa Kepolorejo Kecamatan Magetan Kabupaten Magetan

\section{B. Strategi Produksi}

a) Tempat Produksi Dilakukan Dirumah salah satu team, yang beralamat di Jalan Kalimantan RT 2 RW 2 Desa Keloporejo Kecamatan Magetan Kabupaten Magetan.

b) Survei Pasar dilakukan untuk mendapat bahan baku serta alat dengan harga yang murah. Adapun untuk daun sirihnya kami mendapatkan dipasar sekitar tempat usaha berlangsung.

c) Trial Produk dilakukan untuk memperoleh hasil batik yang memiliki nilai ekonomis serta nilai estetik yang tinggi. Untuk mendapatkan hasil yang memuaskan kami sangat berhati hati dalam menentukan design Batik tulis yang akan kami buat.

d) Produksi :

Dalam Produksi Batik D'Suru dibagi menjadi 3 tahapan :

1.Membuat sketsa motif batik diatas kain putih dengan pensil. Desain batik ini bisa digambar dengan ragam variasi yang diinginkan.

2.Setelah sketsa selesai dibuat, langkah atau tahapan selanjutnya adalah memulai membuat motif dengan getah daun sirih sesuai dengan sketsa motif yang telah digambar menggunakan pensil (daun sirih diletakkan diatas kain putih, dengan digores menggunakan paku sesuai sketsa yang telah digambar).

3.Tahap yang terakhir adalah tahap pewarnaan. Ada beberapa teknik pewarnaan yang bisa digunakan : teknik celup, teknik cat, dll.

Berikut tahapan Pembuatan Batik D’Suru:

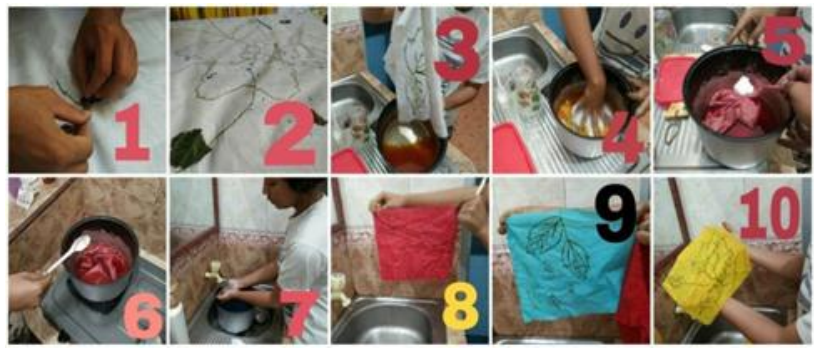

Gambar 1. Tahapan Proses Produksi

e) Pengemasan Pengemasan produk yang kami lakukan adalah menggunakan Plastik Bening dan tempelan Stiker Produk. $\mathrm{Hal}$ ini dipilih karena kemasan terlihat menarik, dan pembeli bisa langsung melihat motif batiknya. Mengenai kemasan kami menggunakan Packing yang menarik, menggunakan Plastik ditambah tempelan Stiker Produk dengan desain modern.

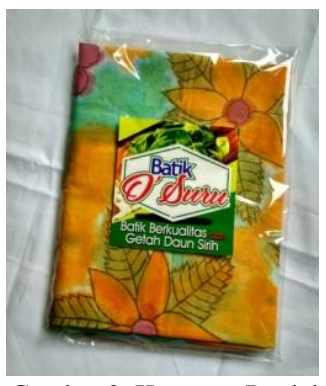

Gambar 2. Kemasan Produk 
Website : http://dayamas.unmermadiun.ac.id/index.php/dayamas

f) Promosi Penggunaan internet bisnis secara online telah tumbuh pesat. Dan hal ini dibuktikan dalam Widiana, et al. (2012) mengenai kepuasan konsumen dalam berbelanja online dapat meningkatkan keyakinan dan kemudahan serta dapat meningkatkan keleluasaan dalam melakukan pilihan produk dan pengiriman yang tepat waktu. Maka dari itu kami melakukan promosi menggunakan media online agar lebih meyakinkan konsumen.

Untuk penjualan kami akan memasarkan Batik D'Suru kami menyebutnya, di Bazzar yang diadakan baik Instansi atau Bazzar yang diadakan di tempat- tempat lain. Selain di Bazaar kami akan memasarkan produk Batik kami mengunakan media dan aplikasi belanja online. Mungkin juga kami akan memasarkan produk Batik kami pada acara Car Free Day yang ada di daerah kami. Serta bisa juga memasarkan produk kami dengan menyewa Stand atau Both di mall- mall di daerah tempat tinggal kami.

Kami juga akan melakukan promosi Word of mouth Mempromosikan secara personal kepada kerabat terdekat, dengan menunjukan berbagai keunggulan produk, seperti kualitas Batik, kualitas pelayanan, Packaging yang menarik, harga yang murah serta promo-promo per-minggunya. Menurut penelitian yang dilakukan Onbee Marketing Research, $89 \%$ konsumen Indonesia lebih mempercayai rekomendasi dari teman dan keluarga pada saat memutuskan untuk membeli sebuah produk.

\section{III.HASIL DAN PEMBAHASAN}

\section{A. Penjualan}

Penjualan Batik D'Suru cukup membuat masyarakat tertarik untuk mencoba produk inovatif ini. Harga jual persatuan Batik D’Suru adalah Rp. 80.000,- . Produksi Batik D’Suru tidak terlalu banyak mengalami kenaikan dan kendalan. Berikut Grafik Produksi Batik D’Suru

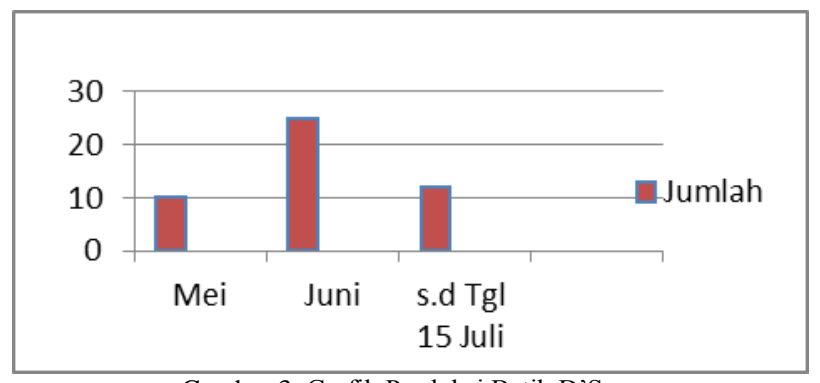

Gambar 3. Grafik Produksi Batik D’Suru

\section{B. Ketercapaian Target Luaran}

Ketercapaian Target Luaran dapat dilihat sebagai berikut :

\begin{tabular}{|c|c|c|c|}
\hline \multirow[b]{2}{*}{ No } & \multirow[b]{2}{*}{ Target } & \multicolumn{2}{|c|}{ KetercapaianTarget $100 \%$} \\
\hline & & Terlaksana & $\begin{array}{l}\text { Belum } \\
\text { Terlaksana }\end{array}$ \\
\hline & Survey Pasar & $100 \%$ & - \\
\hline & $\begin{array}{l}\text { Pemenuhan Alat dan } \\
\text { Bahan }\end{array}$ & $80 \%$ & $20 \%$ \\
\hline & Tempat Produksi & $100 \%$ & - \\
\hline & Pelaksanaan Produksi & $100 \%$ & - \\
\hline & Pemasaran: & $70 \%$ & $30 \%$ \\
\hline & 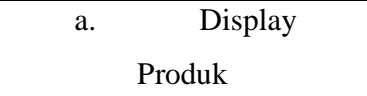 & $70 \%$ & $30 \%$ \\
\hline & 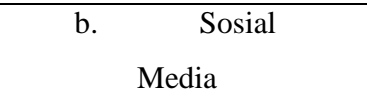 & $100 \%$ & - \\
\hline & $\begin{array}{ll}\text { c. } & \text { Barner }\end{array}$ & $100 \%$ & - \\
\hline & Hak Paten & $50 \%$ & $50 \%$ \\
\hline & Laporan & $80 \%$ & $20 \%$ \\
\hline Tar & t Pencapaian & $85 \%$ & $15 \%$ \\
\hline
\end{tabular}


Website : http://dayamas.unmermadiun.ac.id/index.php/dayamas

\section{Rencana Tahap Selanjutnya}

a) Pemasaran dan Distribusi Produk:

Langkah yang akan segera kami lakukan adalah perluasan pemasaran batik D'Suru. Selama ini kami hanya memasaran di wilayah Madiun dan Magetan saja. Akan coba kami pasarkan di wilayah luar Kota Madiun dan Magetan, seperti Ponorogo dan Ngawi. Sedangkan selama ini kami hanya menggunkan FB untuk berjualan, kami akan membuatkan website yang bisa diakses oleh pembeli. Selain itu kami akan menjual Batik D'Suru bekerjasama dengan E-Commerce seperti Shopee, Bukalapak, dll.

b) Peningkatan Kapasitas Produksi :

Untuk memenuhi banyaknya permintaan dari konsumen, kami berencana untuk menjalin kerja sama dengan mahasiswa teknik mesin untuk menciptakan mesin pres yang dapat digunakan untuk menggoreskan getah daun Sirih. Karena selama ini kami hanya menggunakan Paku, dan itu membutuhkan waktu yang lumayan lama, dan tenaga kerja yang banyak.

c) Hak Paten:

Karena produk yang kami hasilkan merupakan Original Produk/ belum ada dipasaran sebelumnya, kami berencana untuk mendaftarkan Invensi Batik D'Suru atas pembuatan Batik menggunakan getah Daun Sirih.

d) Menambah Variasi Produk:

Karena permintaan pasar yang selalu berkembang, kami berencana untuk menambah variasi Motif, dan warna dari batik yang kami produksi, agar tetap diminati oleh pembeli.

\section{IV.KESIMPULAN DAN SARAN}

A. Saran

Dari Hasil Kegiatan Program Kreatifitas Mahasiswa bidang Kewirausahaan dengan judul Peningkatan Nilai Ekonomis Batik

Tulis dari Daun Sirih, dapat disimpulkan sebagai berikut :

1. Pembuatan Batik dari Daun Sirih ini terbilang cukup mudah, namun dikarenakan belum ada mesin untuk menggoreskan getah Daun Sirih pada kain maka pembuatan batik harus dilakukan secara manual dan lebih lama dibandingkan menggunakan mesin.

2. Kualitas yang dihasilkan tidak kalah jika dibandingkan dengan batik - batik yang ada dipasaran sekarang. Harganya yang sangat terjangkau dapat menjadi nilai utama dari Batik D'Suru ini.

3. Bahan yang digunakan juga mudah didapatkan disekitar tempat tinggal. Daun sirih yang selama ini hanya digunakan sebagai obat dan jamu, dapat meningkat nilai ekonomisnya setelah diolah menjadi batik dan dikemas dengan kemasan yang dapat menarik pelanggan untuk membeli.

B. Saran

1. Melakukan kerja sama dengan mahasiswa Tehnik Mesin untuk menciptakan mesin pres yang digunakan.

2. untuk menggoreskan getah Daun Sirih. Apabila hal ini terwujud maka tingkat produksi Batik D'Suru dapat meninggkat.

3. Karena Batik D'Suru merupakan Batik Original dan belum ada dipasaran sebelumnya, alangkah baiknya untuk mendaftarkan Invensi Batik D’Suru atas pembuatan motif Batik dengan menggunakan Getah Daun Sirih.

\section{UCAPAN TERIMAKASIH}

Ucapan terima kasih kepada pihak yang telah mendukungdan membantu dalam pelaksanaan dan bantuan dana :

- Direktur Jendral Pendidikan Tinggi, Departemen Pendidikan dan Kebudayaan

- Rektor Universitas Merdeka Madiun

- Wakil Rektor Bidang Kemahasiswaan Universitas Merdeka Madiun

- Dekan Fakultas Ekonomi Universitas Merdeka Madiun

- Pembimbing PKM-K Universitas Merdeka Madiun

\section{VI.DAFTAR PUSTAKA}

Arikunto. 2013. Prosedur Penelitian Suatu Pendekatan Praktik. Rineka Cipta, Jakarta.

Nitisusastro, Mulyadi.2010. Kewirausahaan dan Manajemen Usaha Kecil .

Mulyadi, 2004. Akuntansi Manajemen. Yogyakarta: BPFE

Dalimatra, S. 2008. Atlas Tumbuhan Obat Indonesia Jilid 4. Jakarta: Puspa Swara.

Sholikhah, A. (2017). Sirih Merah Menurunkan Glukosa Darah. http://www.pustakatani. Tanggal akses 20 Agustus 2017

Sudewo, B. 2005. Basmi Penyakit dengan Sirih Merah. Jakarta : PT. Agro Media Pustaka.

Widiana, M.E., Supit H., Hartini S., Penggunaan Teknologi Internet dalam Sistem Penjualan Online untuk meningkatkan kepuasan dan pembelian berulan produk batik pada usaha kecil dan menengah di Jawa Timur, Jurnal Manajemen dan Kewirausahaan, Vol 14 No.1, $72-82$. 